\title{
Miniestaquia a partir de minicepas originadas por enxertia de pitangueira adulta
}

\author{
Martha Lucía Peña*, Flávio Zanette, Luiz Antonio Biasi
}

Universidade Federal do Paraná, Curitiba, PR, Brasil

*Autor correspondente; e-mail: marthalupe@bol.com.br

\begin{abstract}
Resumo
O objetivo deste trabalho foi avaliar a viabilidade da técnica de miniestaquia na propagação vegetativa de pitangueira (Eugenia uniflora L.), por meio da produtividade e sobrevivência das minicepas, e do enraizamento das miniestacas oriundas de enxertia e tratadas com diferentes concentrações do ácido indolbutírico (AIB) nas sucessivas coletas. As minicepas foram obtidas usando a enxertia (garfagem em fenda cheia) de garfos coletados da árvore selecionada sobre porta-enxertos formados por sementes coletadas da mesma árvore. Para formação do minijardim, as mudas enxertadas foram cultivadas em tubetes, tiveram suas brotações podadas, mantendo-se um par de folhas em cada brotação. A partir destas minicepas foram realizadas coletas sucessivas de brotações (miniestacas). O delineamento experimental foi inteiramente casualizado, em arranjo fatorial 4 × 4 (quatro épocas de coleta de miniestacas $x$ quatro concentrações de AIB), com quatro repetições de 20 miniestacas como unidade experimental. Obteve-se $100 \%$ de sobrevivência das minicepas após quatro coletas sucessivas de brotações. No período de temperatura mais elevada foi possível realizar duas coletas de brotações, a produtividade foi de 2,4 brotaçoes/minicepa, 598,9 brotações $/ \mathrm{m}^{2}$ na coleta 1, e 2,7 brotaçoes/minicepa, 681,1 brotações $/ \mathrm{m}^{2}$ na coleta 2. A produtividade média foi de 384,4 miniestacas $/ \mathrm{m}^{2} / \mathrm{mês}$. Verificou-se enraizamento adventício inferior a $1,9 \%$. O enraizamento de miniestacas de pitangueira oriundas de enxertia não foi favorecido com o uso de AIB.
\end{abstract}

Palavras-chave: auxina, clonagem, coletas, Eugenia uniflora L., propagação vegetativa

\section{Minicutting technique from ministumps originating from grafting of adult Surinam cherry}

\begin{abstract}
The aim of this study was to evaluate the viability of the minicutting technique in the vegetative propagation of Surinam cherry (Eugenia uniflora L.), through productivity and survival of ministumps, and rooting of minicuttings originating from grafting and treated with different concentrations of indolebutyric acid (IBA) in the successive collections. The ministumps were obtained through grafting (cleft graft) of scions collected from the selected tree onto rootstock formed by seeds collected from the same tree. To create the minigarden, the grafted seedlings were grown in root plugs and their sprouts were pruned, maintaining one pair of leaves on each sprout. From these ministumps, successive collections of sprouts (minicuttings) were made. A completely randomized experimental design was used in a $4 \times 4$ factorial arrangement (four periods of collection of minicuttings $x$ four concentrations of (BA), with four replications and 20 minicuttings as an experimental unit. The survival rate of the ministumps was $100 \%$ after four successive collections of sprouts. In the higher temperature period was possible to carry out two collections of shoots. Mean yield was 2.4 minicuttings/ministump, 598.9 minicuttings $/ \mathrm{m}^{2}$ in the first collection time, and 2.7 minicuttings/ministump, 681.1 minicuttings/ $\mathrm{m}^{2}$ in the second collection time. Mean yield was 384.4 minicuttings $/ \mathrm{m}^{2} / \mathrm{month}$. It was adventitious rooting of less than $1.9 \%$. The rooting of minicuttings from grafting of the Surinam cherry is not favored with the use of IBA.
\end{abstract}

Keywords: auxin, cloning, collections, Eugenia uniflora L., vegetative propagation 


\section{Introdução}

Originária do Brasil, a pitangueira (Eugenia uniflora L.), Myrtaceae, devido à sua adaptabilidade encontra-se nas mais variadas regiões do Brasil e do mundo (Silva, 2006), é recomendada para plantios em reflorestamentos; é considerada espécie ornamental e pode ser utilizada no paisagismo (Lorenzi, 2008); valorizada pelas suas folhas e frutos com óleos essenciais, sais minerais e vitaminas, apresenta potencial de exploração pelas indústrias alimentícias, cosméticas e medicinais (Lira Junior et al., 2007).

A maioria dos pomares de pitangueira existentes são formados a partir de mudas resultantes da propagação por sementes. Estas mudas não são adequadas para formação de pomares comerciais, pois apresentam como inconvenientes grande variabilidade genética e o período de juvenilidade, implicando na frutificação mais tardia do pomar. Sendo assim, recomenda-se a substituição destas mudas por mudas propagadas vegetativamente (Bezerra et al., 2004).

Um dos maiores obstáculos a serem vencidos na propagação vegetativa de uma espécie, de material adulto, é a recuperação da capacidade de enraizamento do material lenhoso (Murayama \& Ferrari, 1993). Uma das mais consistentes expressões da maturação em plantas lenhosas refere-se ao potencial de regeneração, em que a redução da capacidade do enraizamento de propágulos vegetativos, com o envelhecimento ontogenético, tem sido considerada um dos principais efeitos na propagação clonal (Xavier et al., 2013). Este fator gera dificuldades na propagação porque com frequência as características desejadas de uma planta matriz são expressas e avaliadas no estádio adulto (Assis \& Teixeira, 1998), o genótipo a ser reproduzido provém, via de regra, de indivíduos maduros (Ferrari et al., 2004). A propagação vegetativa de árvores adultas requer técnicas de rejuvenescimento de material vegetal para recuperar as condições favoráveis ao enraizamento (Siniscalco \& Pavolettoni, 1988).

A fase adulta naturalmente faz reversão à fase juvenil (rejuvenescimento) durante a reprodução por semente (Hartmann et al., 2011 ). No entanto, reversões (rejuvenescimento) têm sido induzidas em material vegetativo, por exemplo, por meio da enxertia em série (Wendling et al., 2014).

Na fruticultura, a utilização de sementes basicamente está restrita à obtenção de porta-enxertos e ao melhoramento genético (Fachinello et al., 2008). Na miniestaquia é importante considerar que as miniestacas podem ser provenientes de minicepas obtidas pela enxertia, utilizando porta-enxerto de origem seminal e enxerto proveniente da planta adulta selecionada. A principal vantagem do uso da enxertia é a regeneração clonal de árvore adulta com características superiores. A enxertia pode ser utilizada com a finalidade de manter clones desejados pelas suas características de frutificação, florescimento ou crescimento (Hartmann et al., 2011).

O objetivo deste trabalho foi avaliar a viabilidade da técnica de miniestaquia na propagação vegetativa de pitangueira, por meio da produtividade e sobrevivência das minicepas, e do enraizamento das miniestacas oriundas de enxertia e tratadas com diferentes concentrações do ácido indolbutírico (AIB) nas sucessivas coletas.

\section{Material e Métodos}

O trabalho foi conduzido em casa de vegetação, localizada no Departamento de Fitotecnia e Fitossanitarismo, Setor de Ciências Agrárias da Universidade Federal do Paraná, Curitiba, Paraná, Brasil. O trabalho envolveu as seguintes etapas: obtenção do porta-enxerto; preparação do enxerto (garfo); realização da enxertia; seleção dos enxertos; instalação do minijardim; e retirada das brotações para a instalação da miniestaquia.

Foram utilizados como porta-enxertos, plantas provenientes de sementes retiradas de frutos maduros colhidos de uma única planta adulta (15 anos de idade), selecionada no campus do Setor de Ciências Agrárias da UFPR. A semeadura foi realizada no dia 12/11/2009 em tubetes de $240 \mathrm{~cm}^{3}$, colocados em bandejas plásticas de $62 \times 42 \mathrm{~cm}$ com capacidade para 54 tubetes, contendo mistura de substrato comercial vermiculita expandida de granulometria média, Plantmax $\mathrm{HT}^{\circledR}$, e terra 
na proporção de 1:1:1, sendo molhadas com auxilio de mangueira na casa de vegetação. Os porta-enxertos de origem seminal (seedlings), a partir de seis meses de idade, receberam adubação mensal, com $3 \mathrm{~mL}$ no substrato por muda. Foi usada a formulação contendo $4 \mathrm{~g} \mathrm{~L}^{-1}$ de uréia, $10 \mathrm{~g} \mathrm{~L}^{-1}$ de superfosfato simples, $4 \mathrm{~g} \mathrm{~L}^{-1}$ de cloreto de potássio e $10 \mathrm{~mL} \mathrm{L^{-1 }}$ de complexo de micronutrientes (Micros Q-Green Top ${ }^{\circledR}$ ).

Foi realizada a enxertia por garfagem no topo em fenda cheia, método recomendado para vários genótipos de pitangueira no nordeste brasileiro, e no sul do Brasil por Bezerra et al. (2002), Franzon et al. $(2008 ; 2010)$ e Lattuada et al. (2010).

Os porta-enxertos foram utilizados para enxertia quando tinham aproximadamente $30 \mathrm{~cm}$ de altura e 21 meses de idade, no dia 16/08/2011. No ponto da enxertia, aproximadamente a $10 \mathrm{~cm}$ de altura do colo, os porta-enxertos apresentavam diâmetro médio de $3 \mathrm{~mm}$. Procedeu-se à retirada do meristema apical do porta-enxerto, a uma altura de $10 \mathrm{~cm}$, a partir do colo da planta. Em seguida, realizouse um corte longitudinal em fenda cheia com 1 $\mathrm{cm}$ de comprimento. Foram mantidas as folhas existentes no porta-enxerto, abaixo do ponto de enxertia.

Os enxertos foram preparados a partir de estacas semilenhosas (com folhas) de ramos coletados pela manhã da mesma planta adulta que forneceu as sementes para os porta-enxertos de pitangueira para evitar incompatibilidade entre $O$ enxerto e o porta-enxerto. A base dos ramos foi imersa em água, a fim de evitar desidratação, e em seguida, foram preparados os enxertos provenientes da porção do ramo com diâmetro o mais próximo possível ao diâmetro (3 $\mathrm{mm}$ ) do ponto de enxertia no porta-enxerto. Os enxertos utilizados para enxertia possuíam $5 \mathrm{~cm}$ de comprimento, contendo pelo menos duas gemas. Foi realizado corte em bisel duplo, em forma de cunha, com $1 \mathrm{~cm}$ de comprimento na extremidade inferior.

Para o procedimento da enxertia, tanto a excisão do porta-enxerto quanto o corte do enxerto foram feitos com o auxilio de bisturi de forma rápida e procurando a uniformidade dos cortes para facilitar a aderência e evitar o ressecamento dos tecidos. Após a inserção do enxerto sobre a fenda no porta-enxerto, utilizouse fitilho para a amarração. Para impedir a desidratação no ponto de enxertia os enxertos foram envoltos parcialmente com o fitilho, com exceção da gema que ficou exposta. Após a realização da enxertia, o porta-enxerto e o garfo não foram cobertos com saco plástico ou celofane. Os enxertos ficaram na casa de vegetação não climatizada sendo irrigados manualmente com auxilio de mangueira. Durante a condução do experimento foram eliminadas as brotações emitidas no portaenxerto.

Durante 0 acompanhamento do experimento observou-se $\circ$ pegamento dos enxertos os quais apresentavam gemas vegetativas em crescimento, expansão do primeiro par de folhas e emissão de brotações. O pegamento final foi avaliado aos três meses após a enxertia, quando foi realizada a seleção dos enxertos com brotações.

Para a instalação do minijardim no dia 22/11/2011 estes enxertos tiveram suas brotações podadas, mantendo-se um par de folhas em cada brotação, constituindo as 149 minicepas para formação do minijardim. As minicepas foram cultivadas durante 313 dias, em casa de vegetação não climatizada sendo irrigadas manualmente com auxilio de mangueira.

As coletas dos propágulos foram realizadas no minijardim selecionando as brotações que apresentavam um comprimento de aproximadamente $4 \mathrm{~cm}$. As brotações menores que $4 \mathrm{~cm}$ foram mantidas na minicepa para as coletas subsequentes.

As coletas foram efetuadas cada vez que o minijardim tinha quantidade suficiente de brotações para a instalação do experimento de miniestaquia, deste modo foi possível efetuar quatro coletas durante o período do experimento, as datas de coleta foram 05/01, 08/02, 29/03 e $30 / 09 / 2012$. A data de cada coleta permitiu ainda especificar a estação correspondente, ou seja, as coletas 1 e 2 ocorreram no verão, 3 no outono e, 4 na primavera. De acordo com a temperatura média mensal registrada pela estação meteorológica de Curitiba, fornecida pelo Sistema Meteorológico do Paraná (SIMEPAR, 
2013), calculou-se a média para as estações ao longo do ano, obteve-se $20,55^{\circ} \mathrm{C}$ no verão, 16,92 ${ }^{\circ} \mathrm{C}$ no outono, $15,2^{\circ} \mathrm{C}$ no inverno e $17,35^{\circ} \mathrm{C}$ na primavera 2012. As coletas foram efetuadas em diferentes intervalos de tempo, o intervalo entre cada coleta variou de 34 a 185 dias, mantendose a padronização estabelecida quanto à seleção de brotações.

Em cada coleta, todas as brotações com comprimento maior ou igual a $4 \mathrm{~cm}$ foram selecionadas e coletadas pela manhã e imediatamente acondicionadas em bandejas com água para posterior preparo das miniestacas. Em cada coleta foi realizada a contagem de brotações coletadas por minicepa, para a obtenção da produção média do minijardim (brotações por minicepa e brotações por $\mathrm{m}^{2}$ ). Após cada coleta de brotações, as minicepas receberam no substrato $3 \mathrm{~mL}$ da mesma solução aquosa de adubo utilizada para os porta-enxertos.

As miniestacas apicais foram preparadas utilizando-se as brotações, sem desprezar a porção apical e mantendo-se o comprimento aproximado de $4 \mathrm{~cm}$, mantendo-se um par de folhas apicais inteiras, e um par de folhas basais com a área de seu limbo reduzida à metade para a redução da perda de água pela transpiração foliar.

Para manter as condições de turgescência do material vegetal, as miniestacas foram acondicionadas em bandejas com água, e em seguida foram tratadas com o regulador vegetal. A base das miniestacas foi submetida a quatro concentrações de soluções hidroalcoólicas (50\% v/v) de ácido indolbutírico (AIB) (0; 1000; 2000 e $4000 \mathrm{mg} \mathrm{L}^{-1}$ ), por imersão rápida por $5 \mathrm{~s}$. Essas concentrações basearamse em trabalhos com estacas herbáceas de pitangueira (Lattuada et al., 2011 ) e jabuticabeira (Scarpare Filho et al., 1999) e também a partir de experimentos e observações preliminares. Não foi realizado nenhum tratamento de desinfestação previamente à introdução das miniestacas no substrato. O plantio foi realizado em tubetes de $53 \mathrm{~cm}^{3}$, contendo substrato comercial de vermiculita expandida de granulometria média, em casa de vegetação com irrigação intermitente, por microaspersão. O intervalo de irrigação das 8 às $17 \mathrm{~h}$ era de $15 \mathrm{~s}$ a cada 30 min; das 17 às $23 \mathrm{~h}$ de $15 \mathrm{~s}$ a cada $60 \mathrm{~min}$; das 23 às $8 \mathrm{~h}$ de $15 \mathrm{~s}$ a cada três horas. O período de permanência no leito de enraizamento foi de 120 dias.

O delineamento experimental utilizado foi inteiramente casualizado, em arranjo fatorial $4 \times 4$ (quatro épocas de coleta de miniestacas $x$ quatro concentrações de AIB), com quatro repetições, e as unidades experimentais foram formadas por 20 miniestacas.

Foram analisadas as seguintes variáveis: porcentagem de miniestacas enraizadas (miniestacas com indução de primórdios radiciais, com no mínimo $1 \mathrm{~mm}$ de comprimento, podendo ou não apresentar calos); número médio de raízes formadas por miniestaca; comprimento $(\mathrm{cm})$ médio das três maiores raízes formadas por miniestaca; massa de matéria seca de raízes (mg) por miniestaca; porcentagem de miniestacas sobreviventes (miniestacas que não formaram raízes, mas que permaneceram vivas, podendo ou não apresentar calos); porcentagem de retenção foliar; e porcentagem de miniestacas mortas (miniestacas com necrose em toda ou na maior parte de sua extensão).

Para cada variável, inicialmente as variâncias dos tratamentos foram avaliadas quanto a sua homogeneidade pelo teste de Bartlett. Para as variáveis cujas variâncias mostraram-se homogêneas, os dados foram submetidos à análise de variância, e as médias dos tratamentos foram comparadas pelo teste Tukey a $5 \%$ de probabilidade. Enquanto que as variáveis que apresentaram variâncias heterogêneas tiveram os valores originais transformados para posterior análise pelo mesmo teste. Os dados de porcentagem de retenção foliar foram transformados segundo a equação $\operatorname{arcsen} \sqrt{ } \times / 100$. O programa estatístico utilizado foi o Assistat, versão 7.6 beta.

\section{Resultados e Discussão}

Minicepas

As minicepas produzidas via enxertia, cultivadas em tubete de $240 \mathrm{~cm}^{3}$, no minijardim de pitangueira apresentaram alta sobrevivência (100\%) após quatro coletas 
sucessivas de brotações durante o período do experimento. Não houve incidência de doenças que comprometessem a sobrevivência das minicepas. Para pitangueira, não foram encontradas informações sobre a sobrevivência e produtividade de minicepas originadas de enxertia. Entre os estudos com minicepas produzidas via semente de espécies florestais nativas brasileiras, Cunha et al. (2008), para corticeira-do-mato (Erythrina falcata Benth.), após quatro coletas, não observaram mortalidade, em sistema de minijardim em tubete de $110 \mathrm{~cm}^{3}$. Em sistema semi-hidropônico em canaletão com areia Wendling et al. (2007), para erva-mate (llex paraguariensis), após onze coletas, obtiveram 95,6\% de sobrevivência das minicepas, e Pires et al. (2013), para araucária (Araucaria angustifólia), não observaram mortalidade das minicepas.

Os resultados das avaliações das coletas sucessivas de brotações provenientes de minicepas oriundas dos enxertos de pitangueira estão apresentados na Tabela 1. No total, foram realizadas quatro coletas, iniciadas 44 dias após a instalação do minijardim no sistema de tubetes, num intervalo de 313 dias entre a primeira e a última coleta. Observou-se que as minicepas possuem capacidade de emissão de novas brotações após cada coleta de miniestacas.

De acordo com as avaliações, duas coletas, a primeira coleta (44 dias após poda de enxertos) e a segunda coleta (78 dias após poda de enxertos), foram realizadas no período de temperatura mais elevada (média da temperatura ambiente em torno de $20,55{ }^{\circ} \mathrm{C}$ ) em relação às demais coletas. A temperatura possivelmente contribuiu para o desenvolvimento de gemas, e crescimento de brotações(2,4 brotaçoes/minicepa, 598,9 brotações $/ \mathrm{m}^{2}$ na coleta 1 , e 2,7 brotaçoes/ minicepa, 681,1 brotações $/ \mathrm{m}^{2}$ na coleta 2). Esses resultados encontram-se próximos aos relatados para Sapium glandulatum (Vell.) Pax., por Ferreira et al. (2010), que observaram, no verão, a maior produção de miniestacas 12,2 miniestacas/minicepa) em tubete de $205 \mathrm{~cm}^{3}$, 609 miniestacas $/ \mathrm{m}^{2}$

Tabela 1.Produtividade média de brotações de pitangueira em quatro coletas sucessivas realizadas no minijardim durante o período do experimento (janeiro de 2012 a setembro de 2012)

\begin{tabular}{|c|c|c|c|c|c|c|c|c|}
\hline \multirow{3}{*}{ Coleta } & \multirow{3}{*}{$\begin{array}{l}\text { Data } \\
\text { de } \\
\text { coleta }\end{array}$} & \multirow{3}{*}{$\begin{array}{c}\text { Intervalo } \\
\text { entre as } \\
\text { coletas } \\
\text { (dias) }\end{array}$} & \multirow{3}{*}{$\begin{array}{c}\text { Dias após } \\
\text { instalação do } \\
\text { minijardim } \\
\text { (poda enxertos) }\end{array}$} & \multirow{3}{*}{$\begin{array}{c}\mathrm{N}^{\circ} \\
\text { minicepas } \\
\text { sobreviventes }\end{array}$} & \multirow{3}{*}{$\begin{array}{l}\text { Brotações } \\
\text { /coleta } \\
\text { (miniestacas) }\end{array}$} & \multirow{2}{*}{\multicolumn{3}{|c|}{ Produtividade média }} \\
\hline & & & & & & & & \\
\hline & & & & & & $\begin{array}{c}\text { minicepa } \\
\text { /coleta }\end{array}$ & $\begin{array}{c}\mathrm{m}^{2} \\
\text { /coleta }\end{array}$ & $\begin{array}{l}\mathrm{m}^{2} \\
/ \mathrm{mês}\end{array}$ \\
\hline 1 & $05 / 01 / 12$ & - & 44 & 149 & 357 & 2,4 & 598,9 & 408,3 \\
\hline 2 & $08 / 02 / 12$ & 34 & 78 & 149 & 406 & 2,7 & 681,1 & 600,9 \\
\hline 3 & $29 / 03 / 12$ & 50 & 128 & 149 & 348 & 2,3 & 583,8 & 350,3 \\
\hline 4 & $30 / 09 / 12$ & 185 & 313 & 149 & 655 & 4,4 & 1098,8 & 178,2 \\
\hline \multicolumn{2}{|c|}{ Média Geral } & 90 & $\ldots$ & $\ldots$ & 462 & 3,1 & 774,2 & 384,4 \\
\hline
\end{tabular}

Após a terceira coleta foi possível realizar a última coleta de brotações com um intervalo bastante prolongado (185 dias) (Tabela 1). Verificou-se que este intervalo corresponde a um período de temperatura mais baixa (média de temperatura ambiente em torno de $15,2^{\circ} \mathrm{C}$ ) em relação às demais coletas, e não contribuiu para o desenvolvimento de gemas, e crescimento de brotações. Assim, os resultados obtidos para pitangueira indicaram a viabilidade do sistema adotado para obtenção de propágulos juvenis de pitangueira até a terceira coleta em função da produtividade média obtida, e do intervalo entre coletas.

Possivelmente a variação na produtividade de brotações das minicepas de pitangueira também esteja associada ao volume dos tubetes utilizados $\left(240 \mathrm{~cm}^{3}\right)$. Lemos et al. (2010) observaram na pinheira (Annona squamosa L.) que as mudas dos tubetes de $230 \mathrm{~cm}^{3}$ proporcionaram maior capacidade de absorção de nutrientes pelas raízes e, consequentemente, maior desenvolvimento da planta quando comparado às mudas dos tubetes de $150 \mathrm{~cm}^{3}$. Segundo Oliveira et al. (2008) o maior volume de substrato nos tubetes maiores e, consequentemente, a maior disponibilidade de nutrientes ao longo do tempo e o maior espaço para o crescimento das raízes possivelmente tenham favorecido os resultados 
de crescimento observados nas plantas de bananeira (Musa sp.).

Reis et al. (1989), relataram que a restrição do crescimento de raízes provocada pelo volume do recipiente pode promover - desequilíbrio da razão raízes: parte aérea, alterando as respostas fisiológicas das plantas cultivadas. Estes autores afirmaram que 0 pequeno volume dos recipientes, exige, também, a aplicação de concentrações elevadas de nutrientes, devido às perdas por lixiviação, resultantes da necessidade de regas frequentes. De acordo com Hartmann et al. (2011) o ápice da raiz é uma fonte primária de citocininas, as quais desempenham um papel na iniciação e desenvolvimento de brotações.

Souza et al. (2014) trabalhando com minicepas de cedro australiano (Toona ciliata), realizaram três coletas de brotações em intervalos médios de 31 dias, e mostraram que não há exaustão das minicepas com o decorrer do tempo pela coleta sucessiva de miniestacas que resulta na remoção contínua de nutrientes, desde que o fornecimento de nutrientes seja mantido nos tubetes para evitar o esgotamento e queda na produtividade de minicepas. Em outras espécies nativas, como erva-mate (llex paraguariensis), a utilização da solução nutritiva menos concentrada para o sistema semi-hidropônico resulta em produções e sobrevivência de minicepas similares ou até superiores às obtidas com soluções mais concentradas (Wendling et al., 2007). Pires et al. (2013), trabalhando com minicepas provenientes de sementes de Araucaria angustifólia, perceberam a necessidade do desenvolvimento de mais estudos com a espécie, principalmente considerando a nutrição das minicepas e ambiente de propagação. Para pitangueira possivelmente a reposição de nutrientes de forma ainda mais frequente, e a utilização da solução nutritiva em diferentes concentrações poderia contribuir para uma produtividade das minicepas mais constante ao longo do tempo.

Nas minicepas de pitangueira provenientes de mudas originadas de enxertia em tubete, obteve-se uma produtividade média de 3,1 miniestacas por minicepa em cada coleta a cada 90 dias (Tabela 1), em torno de
1,0 miniestaca por minicepa no intervalo médio de 30 dias em quatro coletas. Este valor médio de produção encontra-se próximo ao relatado em estudos a partir de minicepas produzidas por via seminal para cedro-rosa (Cedrela fissilis) por Xavier et al. (2003), para corticeira-domato (Erythrina falcata Benth) por Cunha et al. (2008) que foi de 1,3 miniestaca por minicepa a cada 30 dias em quatro coletas, em minijardim cultivado em tubetes de $200 \mathrm{~cm}^{3}$, e para cedro australiano (Toona ciliata) por Souza et al. (2014), os quais obtiveram a produção de 1,0 miniestaca por minicepa no intervalo médio de 31 dias em três coletas no sistema de tubete.

Possivelmente, as características juvenis do porta-enxerto por ser originário de sementes de pitangueira, influenciaram positivamente na capacidade de emissão de brotações da copa. No caso específico das mudas enxertadas de caramboleira (Averrhoa carambola), Bastos et al. (2005) afirmaram que, embora as mudas enxertadas tenham tecidos maduros na constituição dos garfos retirados de ramos de plantas adultas, elas possuem tecidos com características juvenis do porta-enxerto por serem originários de sementes, e de acordo com os resultados observados concluíram que as características juvenis do porta-enxerto, influenciaram no desenvolvimento da muda enxertada, fazendo com que a muda tivesse elevadas taxas de crescimento em altura, diâmetro do caule, massa fresca e seca da parte aérea e da raiz e, consequentemente, alto vigor.

A produtividade média de brotações de pitangueira por $\mathrm{m}^{2}$ de minijardim a cada mês $(384,4)$ variou entre 178 e 600,9 (Tabela 1), e foi superior ao observado no sistema semihidropônico para Piptocarpha angustifolia Dusen ex. Malme (variando entre 113,4 e 259,2 brotações $/ \mathrm{m}^{2} / \mathrm{mês}$ ) (Ferriani et al., 2011). Dentre os efeitos do porta-enxerto sobre o enxerto Hartmann et al. (2011) destacam que de acordo com as características do porta-enxerto o vigor do enxerto pode ser alterado, ou seja, o portaenxerto pode conferir maior ou menor vigor à copa.

\section{Miniestaquia}

A partir de minicepas obtidas pela 
enxertia, de forma geral, na miniestaquia da pitangueira houve baixo índice de enraizamento das miniestacas, os percentuais de enraizamento foram inferiores a 1,9\% (Tabela 2).

Em virtude da existência de uma ou mais variâncias igual a zero, o programa de análise estatística indicou que não era possível aplicar o teste para as seguintes variáveis: porcentagem de miniestacas enraizadas, número médio de raízes por miniestaca, comprimento médio de

Tabela 2. Porcentagem de miniestacas de pitangueira enraizadas, sobreviventes, retenção foliar e miniestacas mortas, ao longo de quatro coletas sucessivas de miniestacas, tratadas com diferentes concentrações de ácido indolbutírico(1)

\begin{tabular}{|c|c|c|c|c|}
\hline Coleta & $\begin{array}{l}\text { Miniestacas } \\
\text { enraizadas (\%) }\end{array}$ & $\begin{array}{c}\text { Miniestacas } \\
\text { sobreviventes (\%) }\end{array}$ & Retenção foliar (\%) & Miniestacas mortas (\%) \\
\hline 1 & 0,9 & $24,7 \quad b$ & $21,2 \quad b$ & $73,1 \quad b$ \\
\hline 2 & 0,6 & $19,1 \mathrm{~b}$ & $16,9 \mathrm{~b}$ & $80,3 \mathrm{~b}$ \\
\hline 3 & 1,9 & 79,7 a & 75,3 a & $18,4 \mathrm{C}$ \\
\hline 4 & 0,0 & $3,8 \mathrm{c}$ & $2,9 \mathrm{c}$ & 96,3 a \\
\hline \multicolumn{5}{|l|}{$\begin{array}{c}\text { AlB } \\
\left(\mathrm{mg} \mathrm{L}^{-1}\right)\end{array}$} \\
\hline 0 & 0,9 & $41,3 \quad a$ & $37,1 \quad a$ & 57,8 b \\
\hline 1000 & 1,3 & $31,9 \mathrm{ab}$ & $28,7 a b$ & $65,6 \mathrm{ab}$ \\
\hline 2000 & 0,3 & $30,3 \mathrm{~b}$ & $27,8 a b$ & 69,4 a \\
\hline 4000 & 0,9 & $23,8 \quad b$ & $22,7 \quad b$ & 75,3 a \\
\hline CV (\%) & - & 34,55 & 29,6 & 16,9 \\
\hline
\end{tabular}

raízes e massa seca de raízes por miniestaca.

As escassas miniestacas enraizadas apresentaram somente uma raiz, com comprimento variando de 0,1 a 7,5 cm, e massa seca de raízes por miniestaca variando de 1,0 a $30,9 \mathrm{mg}$.

De modo geral, a capacidade de enraizamento das miniestacas possivelmente foi prejudicada pela influência da idade da planta matriz adulta. Este fato provavelmente ocasionou uma condição fisiológica desfavorável das minicepas ao longo do período do experimento, inibindo a indução radicial das miniestacas. Bastos et al. (2009) verificaram que as estacas de caramboleira (Averrhoa carambola) retiradas de plantas juvenis se mostraram mais eficientes na formação de raízes adventícias, quando comparadas com aquelas retiradas de plantas adultas. Os autores afirmaram que tal fato provavelmente ocorreu devido às características fisiológicas das plantas matrizes, pois quando uma planta se encontra na fase adulta, ela apresenta um maior teor de inibidores e menor teor de co-fatores de enraizamento. Segundo Assis \& Teixeira (1998) uma das mais importantes consequências do envelhecimento ontogenético para a clonagem é a redução, ou até mesmo a perda, da capacidade de enraizamento, verificada em plantas adultas.

Grattapaglia \& Machado (1998) recomendam que a retirada de propágulos deva ser feita de preferência a partir de brotações novas que são formadas durante a fase ativa de crescimento da planta, durante os meses mais quentes do ano. Neste estudo, observou-se que foram realizadas duas coletas (coleta 1 e coleta 2) no período de temperatura mais elevada (média da temperatura ambiente em torno de $20,55^{\circ} \mathrm{C}$ ) em relação as demais coletas. A temperatura possivelmente contribuiu para o desenvolvimento de gemas, e crescimento de brotações, porém estas miniestacas não mostraram maior capacidade de enraizamento. Em outro estudo, maiores porcentagens de enraizamento obtidas no verão foram encontradas em outras espécies, como espirradeira (Nerium oleander L.) (Pivetta et al., 2012).

Não foram encontradas informações sobre o enraizamento de miniestacas de pitangueira provenientes de minicepas obtidas por enxertia. Foram encontradas informações sobre 0 enraizamento de miniestacas provenientes de minicepas de origem seminal (seedlings) de outras espécies frutíferas. Marinho et al. (2009) e Altoé et al. (2011), para goiabeira 
e outras espécies do gênero Psidium obtiveram elevado percentual de enraizamento de miniestacas.

Quanto ao enraizamento dasminiestacas oriundas de enxertia, foram observados baixos índices nas três primeiras coletas $(0,9,0,6$ e 1,9\% respectivamente), e ausência de enraizamento na última coleta (coleta 4). Muruyama \& Ferrari (1993), obtiveram material juvenil satisfatório para o enraizamento de estacas de Pinus oocarpa e Pinus caribaea, a partir da terceira enxertia. Siniscalco \& Pavolettoni (1988) realizaram seis enxertias sucessivas, e concluíram que propágulos provenientes de plantas adultas de Eucalyptus trabutii foram revertidos a condições juvenis de forma gradual.

Verificou-se na análise de variância que não houve interação estatisticamente significativa entre os fatores (época de coleta e concentração de ácido indolbutírico) para a variável porcentagem de miniestacas sobreviventes, retenção foliar e miniestacas mortas.

As miniestacas provenientes da terceira coleta apresentaram índice de sobrevivência $(79,7 \%)$ e retenção foliar $(75,3$ $\%)$ significativamente superior aos obtidos nas miniestacas provenientes das demais coletas, e índice de mortalidade significativamente inferior (18,4 \%). As condições fisiológicas da minicepa na terceira coleta provavelmente eram mais favoráveis para sobrevivência das miniestacas. Esta coleta foi realizada no período com média de temperatura ambiente em torno de $16,92^{\circ} \mathrm{C}$. A temperatura possivelmente contribuiu para a sobrevivência das miniestacas.

$\mathrm{Na}$ miniestaquia instalada na última coleta (coleta 4) verificou-se a maior taxa de mortalidade (96,3\%), e a menor taxa de sobrevivência e retenção foliar (Tabela 2).

A porcentagem de enraizamento de miniestacas de pitangueira provenientes de minicepas produzidas via enxertia foi muito baixa $(0,9 \%)$ sem a utilização de AIB. A utilização de AIB não promoveu o enraizamento adventício em miniestacas provenientes de minicepas (enxertos) de Eugenia uniflora L. Em plantas difíceis de enraizar a partir de estacas, faltam substâncias endógenas que podem ser auxinas ou a combinação de determinadas moléculas com auxina que em conjunto promovem enraizamento, e/ou falta sensibilidade das células para responder às substâncias promotoras do enraizamento, mesmo que auxina natural possa ou não estar presente em abundância. Nesse caso, a aplicação de auxinas resulta em pouca ou nenhuma melhoria na resposta de enraizamento (Hartmann et al., 2011).

No entanto, Lattuada et al. (2011), trabalhando com estacas herbáceas de pitangueira coletadas de plantas matrizes juvenis de três anos de idade, observaram 44,15\% de enraizamento com $2000 \mathrm{mg} \mathrm{L}^{-1}$ de AIB. De forma semelhante, Pivetta et al. (2012) concluíram que o ácido indolbutírico nas concentrações de 1000 e $2000 \mathrm{mg} \mathrm{kg}^{-1}$ foi efetivo para aumentar a porcentagem de enraizamento de estacas herbáceas de duas variedades de espirradeira (Nerium oleander L.). Embora, para estacas herbáceas geralmente não seja necessário o uso de auxinas, este regulador vegetal é usado frequentemente para aumentar a porcentagem de estacas que formam raízes, acelerar a iniciação da formação de raízes, aumentar a uniformidade do enraizamento, e desenvolver o sistema radicial de melhor qualidade (Hartmann et al., 2011).

Pode se constatar que houve uma diminuição da porcentagem de miniestacas sobreviventes e retenção foliar, e aumento da porcentagem de miniestacas mortas com a elevação da concentração de AIB (Tabela 2), esta tendência à fitotoxidez está caracterizada pela queda de folhas e posterior morte das estacas de pitangueira. Auxinas utilizadas em concentrações excessivas estimulam a produção de etileno e, consequentemente a queda de folhas (Hopkins, 2000). As auxinas tem capacidade de promover a síntese de etileno pelo aumento da atividade da enzima ACC sintase (Taiz \& Zeiger, 2009).

Em alguns estudos, como o realizado por Lattuada et al. (2011), em estacas de pitangueiras a retenção foliar e a sobrevivência foram prejudicadas pelo incremento nas concentrações de AIB (0 a $\left.6000 \mathrm{mg} \mathrm{L}^{-1}\right)$. Esses autores relataram que este fato possivelmente está relacionado com o efeito fitotóxico do AIB. 
Pivetta et al. (2012) também afirmaram que a concentração de $4000 \mathrm{mg} \mathrm{kg}^{-1}$ de AlB apresentou efeito inibitório ou fitotóxico quando trataram as estacas de espirradeira (Nerium oleander L.).

\section{Conclusões}

Minicepas provenientes de enxertos de pitangueira, cultivadas em tubetes, constituem uma opção para produção de propágulos vegetativos, e a maior produtividade ocorre no período de temperatura mais elevada.

O enraizamento de miniestacas provenientes de minicepas originadas por enxertia de pitangueira é muito baixo e não é favorecido com o uso de ácido indolbutírico.

\section{Referências}

Altoé, J.A., Marinho, C.S., Terra, M.I.da C., Barroso, D.G. 2011. Propagação de araçazeiro e goiabeira via miniestaquia de material juvenil. Bragantia 70: 312-318.

Assis, T.F., Teixeira, S.L. 1998. Enraizamento de plantas lenhosas. In: Torres, A.C., Caldas, L.S., Buso, J.A. (ed.) Cultura de tecidos e transformação genética de plantas. Embrapa-SPI / EmbrapaCNPH, Brasília, Brasil. p.261-296.

Bastos, D.C., Scarpare Filho, J.A., Pio, R., Libardi, M.N., Almeida, L.F.P.de. 2005. Desenvolvimento inicial de mudas enxertadas e de estacas de caramboleira. Revista Brasileira de Fruticultura 27: 338-340.

Bastos, D.C., Scarpare Filho, J.A., Fatinansi, J.C., Pio, R. 2009. Influência da idade biológica da planta matriz e do tipo de estaca caulinar de caramboleira na formação de raízes adventícias. Ciência e Agrotecnologia 33: 1915-1918.

Bezerra, J.E.F., Lederman, I.E., Freitas, E.V.de, Silva Júnior, J.F.da. 2002. Propagação de genótipos de pitangueira (Eugenia uniflora L.) pelo método de enxertia de garfagem no topo em fenda cheia. Revista Brasileira de Fruticultura 24: 160-162.

Bezerra, J.E.F., Lederman, I.E., Silva Junior, J.F.da, Alves, M.A. 2004. Comportamento da pitangueira (Eugenia uniflora L.) sob irrigação na região do vale do rio moxotó, Pernambuco. Revista Brasileira de Fruticultura 26: 177-179.

Cunha, A.C.M.C.M., Wendling, I., Souza Júnior, L. 2008. Miniestaquia em sistema de hidroponia e em tubetes de corticeira-do-mato. Ciência Florestal 18: 85-92.

Fachinello, J.C., Nachtigal, J.C., Kersten, E. 2008. Fruticultura: fundamentos e práticas. UFPEL, Pelotas, Brasil. 176 p.
Ferrari, M.P., Grossi, F.,Wendling, I. 2004. Propagação vegetativa de espécies florestais. Embrapa Florestas, Colombo, Brasil. Documentos 94. $22 \mathrm{p}$.

Ferriani, A.P., Zuffellato-Ribas, K.C., Helm, C.V., Boza, A., Wendling, I., Koehler, H.S. 2011 . Produção de brotações e enraizamento de miniestacas de Piptocarpha angustifolia. Pesquisa Florestal Brasileira 31: 257-264.

Ferreira, B.G.A., Zuffellato-Ribas, K.C., Wendling, I., Koehler, H.S., Nogueira, A.C. 2010. Miniestaquia de Sapium glandulatum (Vell.) Pax com o uso de ácido indolbutírico e ácido naftaleno acético. Ciência Florestal 20: 19-31.

Franzon, R.C., Gonçalves, R.da S., Antunes, L.E.C., Raseira, M.do C.B., Trevisan, R. 2008. Propagação da pitangueira através da enxertia de garfagem. Revista Brasileira de Fruticultura 30: 488-491.

Franzon, R.C., Gonçalves, R.da S., Antunes, L.E.C., Raseira, M.do C.B. 2010. Propagação vegetativa de genótipos de pitangueira (Eugenia uniflora L.) do sul do Brasil por enxertia de garfagem. Revista Brasileira de Fruticultura 32: 262-267.

Grattapaglia, D., Machado M.A. 1998. Micropropagação. In: Torres, A.C., Caldas, L.S., Buso, J.A. (ed.) Cultura de tecidos e transformação genética de plantas. EmbrapaSPI / Embrapa-CNPH, Brasília, Brasil. p.183-260.

Hartmann, H.T., Kester, D.E., Davies Junior, F.T., Geneve, R.L. 2011. Hartmann and Kester's Plant Propagation: principles and practices. Prentice Hall, São Paulo, Brasil. 915 p.

Hopkins, W. 2000. Introduction to Plant Physiology. New York, John Wiley \& Sons, Inc. 512 p.

Lattuada, D.S., Souza, P.V.D.de, Gonzatto, M.P. 2010. Enxertia herbácea em Myrtaceae nativas do Rio Grande do Sul. Revista Brasileira de Fruticultura 32: 1285-1288.

Lattuada, D.S., Spier, M., Souza, P.V.D. de. 2011. Pré-tratamento com água e doses de ácido indolbutírico para estaquia herbácea de pitangueiras. Ciência Rural 41: 2073-2079.

Lemos, E.E.P.de, Salvador, T.de L., Santos, M.Q.C. dos, Rezende, L. de P., Salvador, T. de L., Lima, H.M.A. 2010. Produção de porta-enxertos em tubetes e enxertia precoce da pinheira (Annona squamosa L.). Revista Brasileira de Fruticultura 32: 865-873.

Lira Júnior, J.S., Bezerra, J.E.F., Lederman, I.E., Silva Junior, J.F. 2007 Pitangueira. Empresa Pernambucana de Pesquisa Agropecuária-IPA, Recife, Brasil. 87 p.

Lorenzi, H. 2008. Árvores Brasileiras: Manual de 
identificação e cultivo de plantas arbóreas nativas do Brasil. Instituto Plantarum, Nova Odessa, Brasil. 384 p.

Marinho, C.S., Milhem, L.M.A., Altoé, J.A., Barroso, D.G., Pommer, C.V. 2009. Propagação da goiabeira por miniestaquia. Revista Brasileira de Fruticultura 31: 607-611.

Muruyama, M.Y., Ferrari, M.P. 1993. Propagação vegetativa de pinheiros tropicais. Revista Silvicultura 49: 12 -14.

Oliveira, J.P.de, Costa, F.H.da S., Pereira, J.E.S. 2008. Crescimento de mudas micropropagadas de bananeira aclimatizadas nas condições da Amazônia Sul Ocidental sob a influência de diferentes substratos e recipientes. Revista Brasileira de Fruticultura 30: 459-465.

Pires, P.P., Wendling, I., Brondani, G. 2013. Ácido indolbutírico e ortotropismo na miniestaquia de Araucaria angustifolia. Revista Árvore 37: 393399.

Pivetta, K.F.L., Pedrinho, D.R., Fávero, S., Batista, G.S., Mazzini, R.B. 2012. Época de coleta e ácido indolbutírico no enraizamento de estacas de espirradeira (Nerium oleander L.). Revista Árvore 36: 17-23.

Reis, G.G., Reis, M.G.F., Maestri, M., Xavier, A., Oliveira, L.M. 1989. Crescimento de Eucalyptus camaldulensis, E.grandis e E. cloeziana sob diferentes níveis de restrição radicular. Revista Árvore 13: 1-18.

Scarpare Filho, J.A., Tessarioli Neto, J., Costa Junior, W.H., Kluge, R.A. 1999. Efeito do ácido indolbutírico no enraizamento de estacas herbáceas de jabuticabeira 'Sabara' (Myrciaria jabuticaba) em condições de nebulização. Revista Brasileira de Fruticultura 21: 146-149.

Silva, S. de M. 2006. Pitanga. Revista Brasileira de Fruticultura 28: 1-1

Siniscalco, C., Pavolettoni, L. 1988. Rejuvenation of Eucalyptus $x$ Trabutiiby successive grafting. Acta Horticulturae 227: 98-100.

SIMEPAR. Sistema Meteorológico do Paraná. 2013. O que você precisa. Solicitações dados meteorológicos. Centro Politécnico da UFPR, Curitiba. http://www.simepar.br/site2/ faleconosco <Acesso em 29 Out. 2013>.

Souza, J.S., Barroso, D.G., Silva, M.P.S., Ferreira, D.A., Gravina, G.A., Carneiro, J.G.A. 2014. Produtividade de minicepas de cedro australiano e remoção de nutrientes pela coleta sucessiva de miniestacas. Ciência Florestal 24: 71-77.

Taiz, L., Zeiger, E. 2009. Fisiologia vegetal. Artmed, Porto Alegre, Brasil. 848p.
Wendling, I., Dutra, L.F., Grossi, F. 2007. Produção e sobrevivência de miniestacas e minicepas de erva-mate cultivadas em Sistema semihifropônico. Pesquisa Agropecuária Brasileira 42:289-292.

Wendling, I., Trueman, S.J., Xavier, A. 2014. Maturation and related aspects in clonal forestry - Part II: reinvigoration, rejuvenation and juvenility maintenance. New Forest 45: 473-486.

Xavier, A., Santos, G.A. dos, Wendling, I., Oliveira, M.L. de. 2003. Propagação vegetativa de cedrorosa por miniestaquia. Revista Árvore 27: 139-143.

Xavier, A., Wendling, I., Silva, R.L. 2013. Silvicultura clonal: princípios e técnicas. EdUFV, Viçosa, Brasil. 279p. 